\title{
Urinary Tract Infection in Nephrotic Syndrome: A Hospital Based Cross-Sectional Study
}

\author{
Tanuka Barua ${ }^{\text {* }}$ \\ Razia Sultana ${ }^{2}$ \\ Fazal Karim Babul' \\ Shahed Iqbal ${ }^{1}$ \\ Jhulan Das Sharma ${ }^{3}$ \\ Pradip Kumar Dutta ${ }^{4}$ \\ 'Assistant Professor \\ Department of Pediatrics \\ Chattagram Maa Shishu-O-General Hospital \\ Chittagong, Bangladesh. \\ ${ }^{2}$ Department of Pathology \\ Chattagram Maa Shishu-O-General Hospital \\ Chittagong, Bangladesh. \\ ${ }^{3}$ Department of Pediatrics \\ Southern Medical College \\ Chittagong, Bangladesh. \\ ${ }^{4}$ Department of Nephrology \\ Chittagong Medical College \\ Chittagong, Bangladesh.
}

\begin{abstract}
Background: Urinary Tract Infection (UTI) is a common infection in nephrotic syndrome and have a propensity for long term renal damage. It may be an important cause of poor steroid response. The objective is to study the frequency and etiological organisms of urinary tract infection in idiopathic nephrotic syndrome children. Methods: This Comparative cross-sectional study was conducted in the Pediatric ward of Chittagong Medical College Hospital, Chittagong from 01.01.2009 to 31.12.2009. 52 nephrotic syndrome children diagnosed by serum albumin, serum cholesterol and 24 hours total urinary protein or protein creatinin index were included. After elaborate clinical evaluation, urine for $\mathrm{R} / \mathrm{M} / \mathrm{E}$ and $\mathrm{C} / \mathrm{S}$ was done in all patients. Data regarding pyuria, hematuria, etiological organisms were analyzed by statistical method. Results: UTI was found in $30.8 \%$ nephrotic children and in majority cases $(68.8 \%)$ they were asymptomatic. Male female ratio among UTI patients was 1:1. Mean serum cholesterol in nephrotic syndrome with UTI was higher than that of children without UTI $(418.94 \mathrm{mg} / \mathrm{dl}$ vs $352.03 \mathrm{mg} / \mathrm{dl}$, p value < 0.05 ).Pyuria had poor association with definite UTI ( $p$ value $>0.05$ ). E-coli was the commonest organism isolated in urine culture followed by klebsiella. Conclusion: UTI is one of the most common infections in nephrotic syndrome and may be asymptomatic. It should be screened in every nephrotic child routinely.
\end{abstract}

Key words: Nephrotic syndrome; UTI; Organism.

\section{INTRODUCTION}

Nephrotic syndrome is a common chronic disease in childhood characterized by heavy proteinuria, hypoalbuminemia, hyperlipidemia and odema ${ }^{1}$. Incidence of idiopathic nephrotic syndrome in western countries varies between 2-7 cases with prevalence rates of nearly 16 cases per $100000^{2}$. Infection is one of the most important complication in nephrotic syndrome specially in developing countries as ours. Being the commonest cause of mortality, infection results in poor response to steroid and frequently results in relapse in a child who has already attained remission ${ }^{3,4}$. Infection in nephrotic syndrome may be vague or non-specific which may delay early diagnosis having various effect on patient with nephrotic syndrome ${ }^{5}$.

Of all infections, urinary tract infection are of special interest because most of the urinary tract infection in nephrotic syndrome are asymptomatic ${ }^{6}$. Besides, in general, younger the child, the sign symptoms of urinary tract infection are less localizing ${ }^{7}$. So it is often undiagnosed and important cause of prolonged hospital stay having a propensity for long term renal damage ${ }^{3,8}$. Like other infections UTI in nephrotic syndrome is associated with significantly lower serum albumin and also with higher serum cholesterol level ${ }^{3,9}$. Hypercholesterolemia may have direct role in precipitation of infection as it inhibit the lymphocytic function. 
UTI in nephrotic syndrome can be caused by gram negative bacteria such as E coli, klebsiella, enterobactor species, proteus species and gram positive bacteria, enterococcus species, staphylococcus saphrophyticus. E coli is the most common organism causing both community as well as hospital acquired $\mathrm{UTI}^{10}$. Health care associated UTI (Mostly related to urinary catheterization) involve much broader range including $\mathrm{E}$ coli (27\%), Klebsiella (11\%) Pseudomonus (11\%) Enterococcas (7\%) Candida (9\%) and others ${ }^{11,12}$. UTI due to staphylococcus aureus occur secondary to blood-born infections ${ }^{13}$.

There is no published data in our country regarding incidence, etiological organism causing UTI in childhood nephrotic syndrome. Although there have been some parallel studies regarding prevalence of UTI in nephritic syndrome. But still there is scarcity of information about our changing etiological organism. We conducted a study to analyze the clinical spectrum of UTI in children with nephrotic syndrome with intention to define the frequency and etiology of UTI in nephrotic syndrome. Knowledge regarding this is important not only for better management of nephrotic children but also for prevention of UTI.

\section{MATERIALS AND METHODS}

It was a hospital based comparative cross-sectional study conducted in pediatric ward of Chittagong Medical College from January, 2009 to December, 2009. A total 60 nephrotic syndrome children admitted during study period were selected, 8 were lost for follow up. Nephrotic syndrome was diagnosed by low serum albumin, high serum cholesterol and first morning PCI ( $>2 \mathrm{mg}$ protein $/ \mathrm{mg}$ creatinine or $>200 \mathrm{mg}$ protein $/ \mathrm{mmol}$ creatinine) or 24 hours total urinary protein ( $>$ $960 \mathrm{mg} / \mathrm{m}^{2} /$ day $)^{2,14}$.

\section{Objective}

i) To observe the frequency of UTI in nephrotic syndrome children.

ii) To identify etiological organisms causing UTI in nephrotic syndrome.

\section{Inclusion criteria:}

- Nephrotic syndrome children aged 2-6 years presented with typical presentation.

\section{Exclusion criteria:}

- Age $<2$ years, $>6$ years.

- Nephrotic syndrome with atypical presentation- hypertension, gross hematuria.

- Nephrotic syndrome with features of complications other than UTI.

- $\mathrm{H} / \mathrm{O}$ of taking antibiotic during last 15 days prior to $\operatorname{admission}^{15}$.

- Secondary nephrotic syndrome.
After taking informed written consent and physical examination of patients, midstream urine sample was collected in proper aseptic method and sent to laboratory for microscopic $\&$ culture sensitivity test. In case of collection failure, urine was collected by sterile catheterization. For diagnosis of UTI, pus cell $>5$ per high power field was defined as pyuria considered suggestive of $\mathrm{UTI}^{16}$. A positive culture confirming UTI was defined as midstream clean voided specimen with isolation of $10^{5}$ or $>10^{5}$ colony forming unit $/ \mathrm{ml}(\mathrm{cfu} / \mathrm{ml})$ of single organism in asymptomatic patient and $10^{4} \mathrm{cfu} / \mathrm{ml}$ in symptomatic patient ${ }^{17}$. In case of urine collection by catheterization, $5 \mathrm{I} 10^{4}$ or greater $\mathrm{cfu} / \mathrm{ml}$ of single organism was significant for $\mathrm{UTI}^{18}$. Data regarding pyuria, etiological organisms and other biochemical parameter were recorded in case record form and statistically analyzed. Protocol was ethically reviewed and approved by Ethical Review Committee of Chittagong Medical College.

\section{RESULTS}

The prevalence of UTI in our study was $30.8 \%$ (16 out of 52 cases) (Figure 1). Out of 16 nephrotic syndrome with UTI patients (Group A) 50\% $(\mathrm{n}=8)$ had UTI. Male : Female ratio $=$ $1: 1$. In case of nephrotic syndrome without UTI (Group B), out of $36,61.1 \%(n=22)$ were male and $38.9 \%(n=14)$ were female (Figure 2).

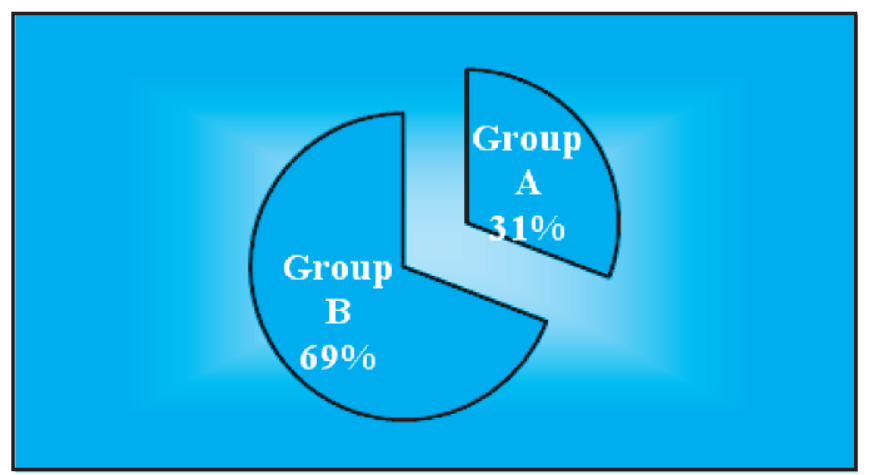

Figure 1: Distribution of UTI (Group A: Nephrotic syndrome with UTI Group B: Nephrotic syndrome without UTI).

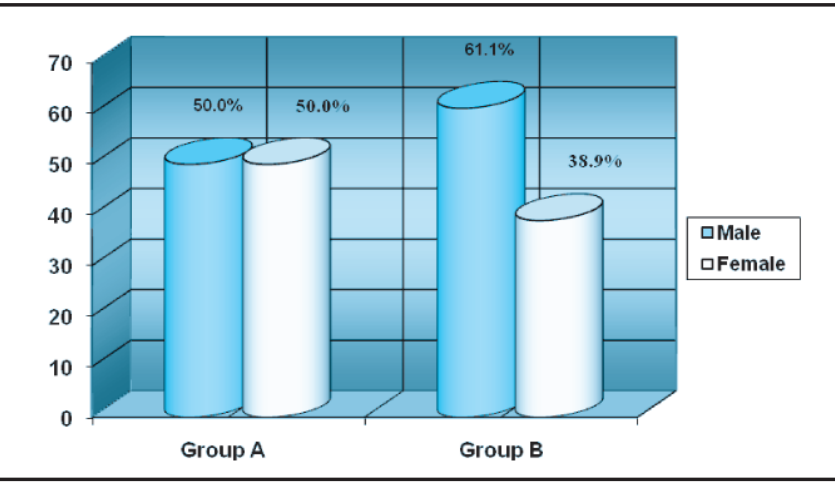

Figure 2 : Distribution of sex among the study groups (Group A: Nephrotic syndrome with UTI Group B: Nephrotic syndrome without UTI). 
Most of the patients were asymptomatic. Out of 16 UTI patients, $68.8 \%(\mathrm{n}=11)$ patients were asymptomatic, only $31.2 \%(n=5)$ patients presented with symptoms (Table 1$)$.

Table 1: Distribution of clinical profile among the UTI patients $(\mathrm{n}=16)$.

\begin{tabular}{lcc} 
Clinical Profile & Frequency & Percentage (\%) \\
Symptomatic & 05 & 31.2 \\
Asymptomatic & 11 & 68.8 \\
Total & 16 & 100.0 \\
\hline
\end{tabular}

Mean serum albumin was $2.14 \mathrm{gm} / \mathrm{dl}( \pm 0.58)$ in nephrotic children with UTI (Group A) patients and $2.02 \mathrm{gm} / \mathrm{dl}( \pm 0.45)$ in nephrotic children without UTI (Group B) patients that was not statistically significant ( $\mathrm{p}$ value was $>0.05$, Table 2 ). Mean serum cholesterol in nephrotic syndrome with UTI (Group A) patients was $418.94 \mathrm{mg} / \mathrm{dl}( \pm 102.28)$ which is significantly higher than that of children without UTI (Group B) in whom it was $352.03 \mathrm{mg} / \mathrm{dl}( \pm 24.05)$ that was statistically significant $(\mathrm{p}<$ $0.05)$ (Table 2).

Table 2 : Biochemical findings among the study groups (With $\mathrm{t}$ - test significance).

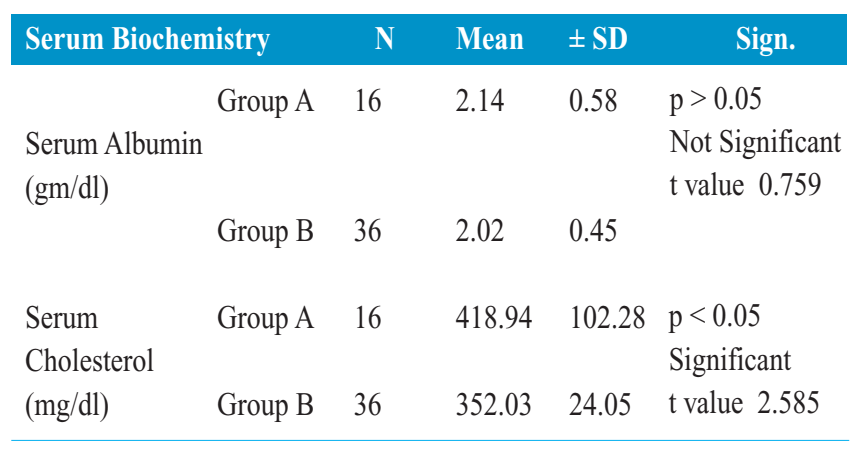

Microscopic examination of urine showed pyuria in $62.5 \%$ $(n=10$ out of 16$)$ nephrotic syndrome with UTI patients (Group A) and in $52.8 \%(n=19$ out of 36$)$ nephrotic syndrome without UTI (Group B) (Table 3, p value $>0.05$, not significant). Microscopic hematuria was found in $31.2 \%$ ( $n=5$ out of 16 ) of UTI patients (Group A) \& in $16.7 \%$ ( $n=6$ out of 36 ) of without UTI patients (Group B) that was not statistically significant (Table $4, \mathrm{p}$ value $>0.05$ ).

Table 3 : Distribution of pyuria among the study groups (with $\chi^{2}$ test significance) (Group A: Nephrotic syndrome with UTI, Group B: Nephrotic syndrome without UTI).

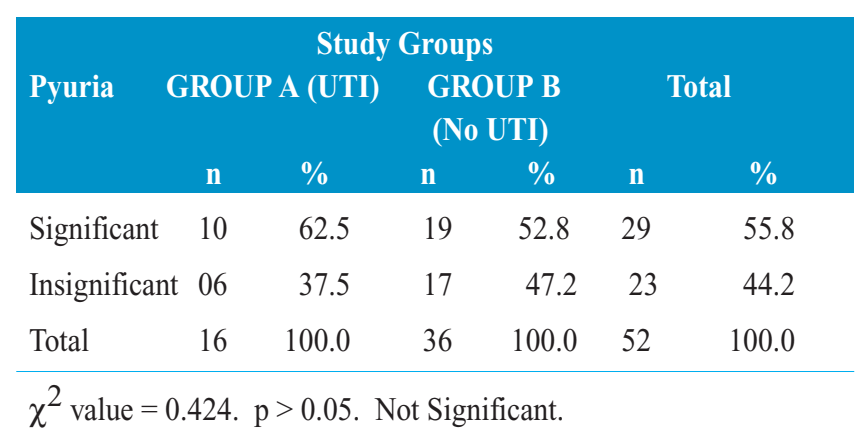

Table 4 : Distribution of microscopic hematuria among the study groups (with $\chi^{2}$ test significance) (Group A: Nephrotic syndrome with UTI, Group B: Nephrotic syndrome without UTI).

\begin{tabular}{lrrrrrr}
\multicolumn{9}{c}{ Study Groups } \\
$\begin{array}{l}\text { Microscopic } \\
\text { Hematuria }\end{array}$ & \multicolumn{1}{c}{ GROUP A } & \multicolumn{2}{l}{ GROUP B } & \multicolumn{2}{c}{ Total } \\
& \multicolumn{1}{c}{ GRO } \\
n & $\%$ & n & $\%$ & n & $\%$ & \\
Significant & 05 & 31.2 & 06 & 16.7 & 11 & 21.2 \\
Insignificant & 11 & 68.8 & 30 & 83.3 & 41 & 78.8 \\
Total & 16 & 100.0 & 36 & 100.0 & 52 & 100.0 \\
\hline
\end{tabular}

$\chi^{2}$ value $=1.412 . \mathrm{p}>0.05$. Not Significant.

Causative organisms of UTI isolated in our study were E coli $(50 \%$, $\mathrm{n}=8)$ followed by Klebsiella $(25 \%, \mathrm{n}=4)$, Coliforms $(18.7 \%, \mathrm{n}=3) \&$ Proteus $(6.3 \%, \mathrm{n}=1)$ (Table 5).

Table 5 : Common organisms of UTI.

\begin{tabular}{lcc} 
Organisms & Frequency & Percentage (\%) \\
E. Coli & 08 & 50.0 \\
Klebsiella & 04 & 25.0 \\
Coliform & 03 & 18.7 \\
Proteus & 01 & 6.3 \\
Total & 52 & 100.0 \\
\hline
\end{tabular}

\section{DISCUSSION}

The prevalence of UTI in our study was 30.8\% (Figure 1) which is consistent with previous studies $13.7 \%$ by Gulati S, Gupta A et al $46 \%$ by Sengutthuvan P, Ravana K et al and this is much higher against $1-3 \%$ reported in general pediatric population $^{8,19,20}$. But attack of UTI was equal in male \& female (Figure 2) which is not supported by many other studies $^{21}$. The important finding of our study was most of UTI patients $(68.8 \%)$ were asymptomatic (Table 1$)$ that is consisted with standard reference ${ }^{3,9}$.

Gulati S, Kher V et al and Gulati S, Arora P et al shown that UTI in nephrotic children is associated with lower serum albumin and higher serum cholesterol ${ }^{3,9}$. In our study incidence of UTI was more in children with high serum cholesterol level. Mean serum cholesterol in nephrotic syndrome with UTI was $418.94 \mathrm{mg} / \mathrm{dl}$ which is significantly higher than that of children without UTI in whom it was $352.03 \mathrm{mg} / \mathrm{dl}(\mathrm{p}<0.05)$. But we found no significant difference in serum albumin level of two groups (Table 2).

We found poor association of pyuria with definite UTI. Microscopic examination of urine showed presence of pyuria in $62.5 \%$ culture positive cases and in $52.8 \%$ culture negative cases (Table 3, p value $>0.05$ ). This is consistent with observation of Rahman M, Rahman $\mathrm{KM}^{21}$. No association was also found in case of microscopic hematuria (Table 4). This microscopic hematuria may be due to nephrotic syndrome itself. 
Most common organism of UTI in nephrotic children isolated in our study was E coli followed by Klebsiella, Coliforms \& Proteus (Table 5). According to Gulati S, Kher V et al Gulati $\mathrm{S}$, Arora $\mathrm{P}$ et al and Emilia M, Dantas $\mathrm{S}$ et al $\mathrm{E}$ coli is the commonest organism followed by Klebsiella ${ }^{3,9,22}$. Our findings is supported by that study.

\section{CONCLUSION}

We conclude that children with nephrotic syndrome are frequently predisposed to UTI and in most cases it is asymptomatic, often undiagnosed. E. coli is the commonest organism causing UTI followed by klelbsiella. All nephrotic children should be screened for UTI routinely for proper management and to avoid prolonged hospital stay, thereby to prevent long term renal damage.

\section{DISCLOSURE}

All the authors declared no competing interest.

\section{REFERENCES}

1. Nanjundaswany HM, Phadke KD. Steroid sensitive Nephrotic syndrome. Indian J of Pediatr. 2002;69:1059-1063.

2. Consensus statement on management and audit potential for steroid responsive nephrotic syndrome : Report of a workshop by the British Association for Paediatric Nephrology and Research Unit, Royal College of Physicians. Arch Dis Child. 1994;70:151-157.

3. Gulati S, kher V, Arora A, Gupta S, Kale S. Urinary tract infection in nephrotic syndrome. Pediatr Infect Dis J. 1996;15:237-240.

4. Wolfish, P Melaine, P Philipps, E Rassies. Role of respiratory viruses in exacerbations of primary nephrotic syndrome. The J of Pediatr. 1986; $108: 378-382$

5. Srivastava RN, Moudgil A, Khurana O. Serious infections and mortality in nephrotic syndrome. Indian Pediatr. 1987;24:1077-1080.

6. Alwadhi RK, Mathew JL, Rath B. Clinical profile of children with nephrotic syndrome not on glucocorticoid therapy but presenting with infection. J Paediatr Child Health. 2004;40:28-32.

7. George H and McCracken JR. Diagnosis and management of acute urinary tract infection in infants and children. The Pediatr Infect Dis J. 1987;6:107-112.

8. Gulati S, Gupta A, Kher V, Sharma RK. Steroid response pattern in Indian children with nephrotic syndrome. Acta Paediatr. 1995;83:530-533.

9. Gulati S, Arora P, Sharma RK, Kher V, Gupta A, Rai PK. Spectrum of Infections in Indian Children with Nephrotic Syndrome. Pediatr Nephrol. 1995;9:431-434.

10. Sobel JD, Kaye D. Urinary Tract Infections. In: Mandell GL, Bennet JE, Dolin R editors. Mandell, Douglas and Bennet's Principles and Practice of Infectious Diseases. Philadelphia, USA: Charchill Livingstone Elsevier Publications. 2010;7(1):958-972.

11. Silvert D, Ricks P, Edwards J et al. Anti-microbial resistance patterns associated with Health-care Infections: Summary of data reported to the National Health-care safety network at the centers for disease control and prevention, 2009-2010. Infect Control Hosp Epidemiol. 2013;34(1):1-14.

12. Bagshaw SM, Laupland KB. Epidemiology of intensive care unit acquired urinary tract infections. Current Opinion in Infectious Diseases. 2006;19(1):67-71.

13. Lane DR, Takhar SS. Diagnosis and Management of Urinary Tract Infection and Pyelonephritis. Emmergency medicine clinics of North America. 2011;29(3):539-552

14. Eddy AA and Symons JM. Nephrotic Syndrome in Childhood. The Lancet. 2003;362:629-636.

15. Holford NHG. Pharmacokinetics \& Pharmacodynamics: Rational Dosing \& Time Course of Drug Action. In: B G Katzung, editor. Basic \& Clinical Pharmacology. United States: McGraw Hill Companies. 2004;9:34-50.

16. Swash M. In : Hutchison's Clinical Methods. London: W B Saunders.1995;20:129-132.

17. Elder JS. Urinary tract infection. In: Kliegman, Behrman, Jenson, Stanton, editors. Nelson textbook of Pediatrics. Philadelphia: Kliegman Saunders. 2007; 18:2223-2225.

18. Dulczak S, Kirk J. Overview of the Evaluation, Diagnosis and Management of urinary tract infections in Infants and Children. UrolNurs. 2005;25(3):185-192.

19. Senguttuvan P, Ravanan K, Pravu N, Tamilarasi V. Infection encountered in childhood nephrotics in a paediatric renal unit. Indian J Nephrol. 2004; $14: 85-88$

20. Uhari M, Nuutinen M. Epidemiology of symptomatic infection of the urinary tract in children. Br Med J. 1988;297:450-452.

21. Rahman M, Rahman KM. Urinary tract infection in school children. BMRC Bulletin. 1979;2:67-70.

22. Emilia M, Dantas S, Vera H, Maria DF and Yassuhiko O. Influence of nephritic state on the infectious profile in childhood idiopathic nephoitic syndrome. Rev Hosp Clin Fac Med S Paulo. 2004;59 (5);273-278. 